\title{
Myocardial stunning occurs during intermittent haemodialysis for acute kidney injury
}

Huda Mahmoud ${ }^{1,2^{*}}$, Lui G. Forni ${ }^{3}$, Christopher W. Mclntyre ${ }^{4}$ and Nicholas M. Selby ${ }^{1,2}$

@ 2017 The Author(s). This article is an open access publication

\section{Dear Editor,}

The choice of renal replacement therapy (RRT) modality in acute kidney injury (AKI) remains controversial with proponents of continuous therapies citing haemodynamic instability as a major disadvantage of intermittent techniques [1]. Haemodynamic change during chronic haemodialysis results in subclinical myocardial ischaemia [2], leading to permanent reductions in left ventricular (LV) function and contributing to adverse patient outcomes [3]; there are no existing studies examining whether similar changes occur during acute RRT. We write to describe our proof-of-concept study examining whether this process of myocardial stunning occurs during acute RRT for AKI.

With research ethics committee approval and informed consent, 11 patients requiring RRT for AKI in a level 2 setting were studied over the course of a single 4-h intermittent haemodialysis (IHD) session. Echocardiography of the left ventricle using four- and two-chamber views (LV) was performed before, during $(225 \mathrm{~min})$ and $30 \mathrm{~min}$ after dialysis. Regional (12 LV segments) and global longitudinal strain (GLS) at each time point were determined by $2 \mathrm{D}$ speckle tracking analysis, a sensitive technique to detect changes in regional and global LV contractility. Our primary endpoint was the development of new LV regional wall motion abnormalities (RWMAs) during dialysis, defined as LV segments that displayed $\geq 20 \%$ decrease in peak systolic longitudinal strain as compared to individual segmental pre-dialysis values [4]. In the chronic haemodialysis population, two or more RWMAs occurring during dialysis strongly associate with adverse

\footnotetext{
*Correspondence: huda.mahmoud@nottingham.ac.uk

2 Department of Renal Medicine, Royal Derby Hospital, Uttoxeter Road, Derby DE22 3NE, UK
}

Full author information is available at the end of the article patient outcomes in a dose-dependent manner [5]. Haemodynamic monitoring was performed throughout dialysis using Thoracic Bioreactance (NICOM; Cheetah Medical, Israel). Stroke volume (SV), cardiac output (CO), blood pressure (BP) and total peripheral resistance were recorded every $15 \mathrm{~min}$. High-sensitivity troponin- $\mathrm{T}$ levels were measured before and $6 \mathrm{~h}$ after dialysis.

The mean age of the participants was $59 \pm 15$ years, nine were male and five were diabetic. Five patients had chronic hypertension, three patients had a history of ischaemic heart disease and four patients had pre-existing CKD-G3 (baseline eGFR 30-60 ml/min/1.73 $\mathrm{m}^{2}$ ). In the group overall baseline eGFR was $79.4 \pm 29.5 \mathrm{ml} /$ $\min / 1.73 \mathrm{~m}^{2}$. All patients had AKI stage 3 with a median serum creatinine concentration at presentation of $882 \mu \mathrm{mol} / \mathrm{L}$ (IQR $801 \mu \mathrm{mol} / \mathrm{L}$ ); baseline serum creatinine was $94 \mu \mathrm{mol} / \mathrm{L}$ (IQR $44 \mu \mathrm{mol} / \mathrm{L}$ ). In four patients, the cause of AKI was determined by renal biopsy (one each of rhabdomyolysis, myeloma, plasma-cell leukaemia and anti-glomerular basement membrane disease). Of the remaining patients, five had AKI in the setting of sepsis, one had cardio-renal syndrome and one had renal artery thrombosis.

All patients commenced RRT within the first $48 \mathrm{~h}$ of hospital admission (four patients day 0, five patients day 1 , two patients day 2) and completed $4 \mathrm{~h}$ of dialysis for study sessions. No patients required inotropic or ventilatory support, and the median Sequential Organ Failure Assessment (SOFA) score on day of study was 6(IQR2).

All patients developed two or more new RWMAs during dialysis with a median number of affected LV segments of 5(IQR 4-6). These changes persisted after dialysis (median number of RWMA 4, IQR 3-6). Global LV contractility also declined, with GLS falling from a normal pre-dialysis level of $-17.8 \pm 3.7 \%$ to an abnormal level during dialysis

\section{伨




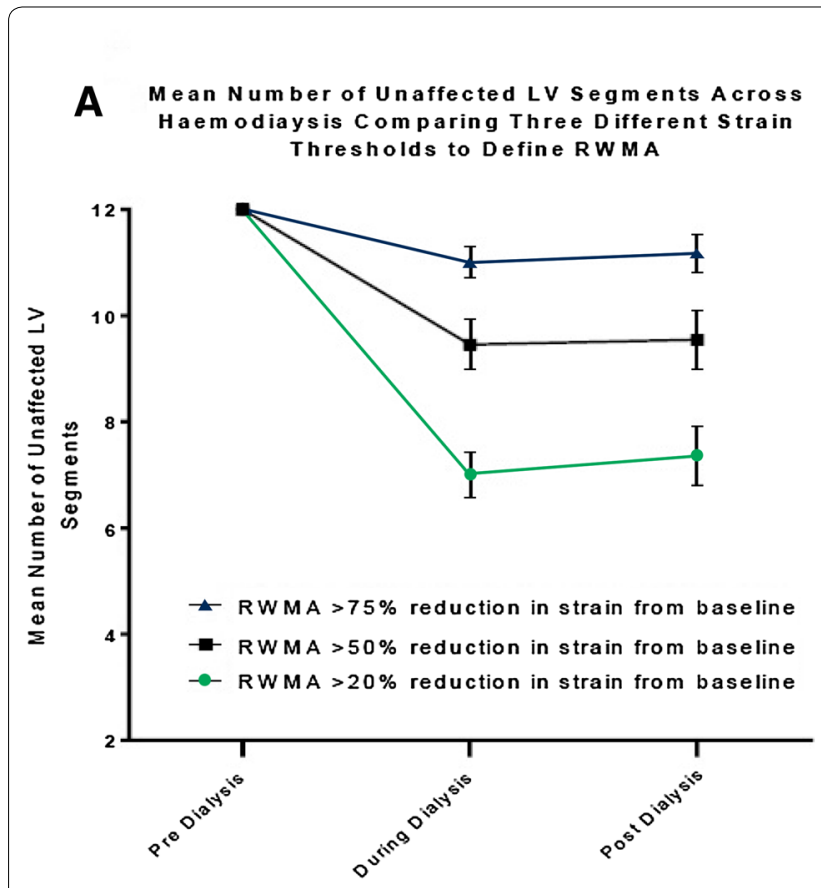

B Global Longitudinal Strain (Mean $+/$-SD) Across

a Dialysis session

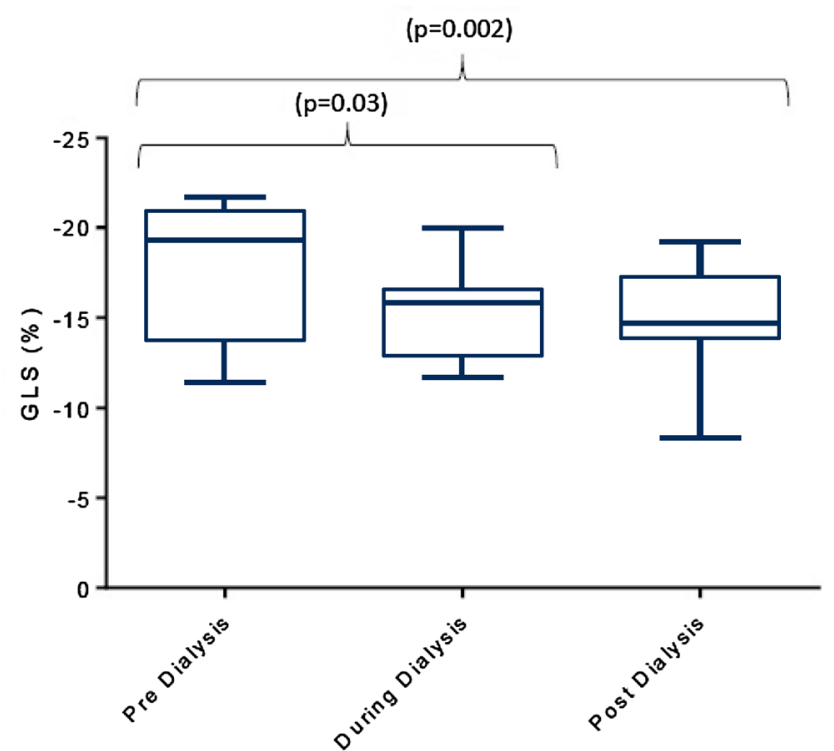

Fig. 1 a The number of unaffected left ventricular segments during dialysis, demonstrating the onset of regional LV dysfunction. All patients experienced new RWMAs during dialysis using the pre-defined definition of $\geq 20 \%$ reduction in segmental longitudinal strain, hence we performed a sensitivity analysis in which new RWMAs were defined at $\mathrm{a} \geq 50 \%$ reduction and $\geq 75 \%$ reduction in segmental strain. At $50 \%$ threshold, results were broadly similar with 9 out of the 11 patients demonstrating two or more new RWMAs. A 75\% threshold appeared too stringent. b Global longitudinal strain (a measure of global LV contractility) before, during and after dialysis. Significant deterioration in GLS was seen both during and 30 min after dialysis

$(-15.3 \pm 2.3 \%, p=0.03)$ and remaining low in the postdialysis period $(-14.8 \pm 2.8 \%, p=0.002)$. These data are summarised in Fig. 1. High-sensitivity troponin-T values were significantly higher $6 \mathrm{~h}$ after dialysis; $56 \mu \mathrm{g} / \mathrm{l}$ (IQR $394 \mu \mathrm{g} / \mathrm{l})$ versus $39 \mu \mathrm{g} / \mathrm{l}(\mathrm{IQR} 216 \mu \mathrm{g} / \mathrm{l}), p=0.003$. These changes occurred on a backdrop of modest ultrafiltration (mean UF rate $5 \pm 3 \mathrm{ml} / \mathrm{h} / \mathrm{kg}$, mean UF volume $1.4 \pm 1 \mathrm{~L}$ ) and without significant change in mean blood pressure, although the lack of change in mean blood pressure values masked individual variation. The mean fall in SBP during dialysis (pre-dialysis to nadir) was $13.8 \pm 8 \mathrm{mmHg}$ and seven patients had an episode of intradialytic hypotension. Full blood pressure and haemodynamic data are included as supplementary material.

In summary, these results show that IHD for AKI can result in acute deterioration in regional and global LV contractility. We suggest that the segmental nature of LV dysfunction coupled with an acute rise in cardiac injury biomarkers are suggestive of subclinical myocardial ischaemia, similar to that directly visualised (using positron emission tomography and arterial spin-labelling MRI) during chronic haemodialysis. This process may be relevant to the poor patient outcomes that are observed in AKI patients requiring RRT or indeed the intolerance that some observe with intermittent therapies; however, further studies (currently planned) are needed to determine whether this process impacts on longer-term cardiac function and ultimately patient outcomes. These is also an important question as to whether the process of RRT-induced cardiac dysfunction occurs to the same extent during continuous and intermittent therapies; this may further inform the ongoing debate around RRT modality choice for critically ill patients with AKI.

\section{Electronic supplementary material}

The online version of this article (doi:10.1007/s00134-017-4768-2) contains supplementary material, which is available to authorized users.

\section{Author details}

${ }^{1}$ Centre for Kidney Research and Innovation, School of Medicine, University of Nottingham, Nottingham, UK. ${ }^{2}$ Department of Renal Medicine, Royal Derby Hospital, Uttoxeter Road, Derby DE22 3NE, UK. ${ }^{3}$ Department of Intensive Care and Faculty of Health and Medical Sciences, University of Surrey, Guildford, UK. ${ }^{4}$ Schulich School of Medicine and Dentistry, London, ON, Canada.

\section{Compliance with ethical standards}

\section{Conflicts of interest}

None of the authors have conflicts of interest to declare.

\section{Open Access}

This article is distributed under the terms of the Creative Commons Attribution-NonCommercial 4.0 International License (http://creativecommons.org/ 
licenses/by-nc/4.0/), which permits any noncommercial use, distribution, and reproduction in any medium, provided you give appropriate credit to the original author(s) and the source, provide a link to the Creative Commons license, and indicate if changes were made.

\section{Accepted: 8 March 2017}

Published online: 28 March 2017

\section{References}

1. Augustine JJ, Sandy D, Seifert TH, Paganini EP (2004) A randomized controlled trial comparing intermittent with continuous dialysis in patients with ARF. Am J Kidney Dis 44(6):1000-1007
2. Buchanan C, Mohammed A, Cox E et al (2016) Intradialytic cardiac magnetic resonance imaging to assess cardiovascular responses in a short-term trial of hemodiafiltration and hemodialysis. J Am Soc Nephrol 28:1-9

3. Burton JO, Jefferies HJ, Selby NM, McIntyre CW (2009) Hemodialysisinduced cardiac injury: determinants and associated outcomes. Clin J Am Soc Nephrol 4(5):914-920

4. Lang RM, Badano LP, Mor-Avi V et al (2015) Recommendations for cardiac chamber quantification by echocardiography in adults: an update from the American Society of Echocardiography and the European Association of Cardiovascular Imaging. J Am Soc Echocardiogr 28(1):1-39 (e14)

5. Assa S, Hummel YM, Voors AA et al (2012) Hemodialysis-induced regional left ventricular systolic dysfunction: prevalence, patient and dialysis treatment-related factors, and prognostic significance. Clin J Am Soc Nephrol 7(10):1615-1623 